\title{
Sustainable Mobility: Environmental and Economic Analysis of a Cable Railway, Powered by Photovoltaic System
}

\author{
D. Gattuso, A. Greco, C. Marino, A. Nucara, M. Pietrafesa* and F. Scopelliti
}

Dipartimento di Ingegneria dell'Informazione, delle Infrastrutture e dell'Energia Sostenibile (DIIES) - University "Mediterranea" of Reggio Calabria

Email: matilde.pietrafesa@unirc.it

\begin{abstract}
Nowadays, the massive use of fossil fuels, required to satisfy the energy needs of modern society, has caused evident climate changes which are dangerously destabilizing the ecosystem.

Currently, among the sectors responsible for the increased energy consumption are the building industry and the transportation systems. As regards the latter, in particular, the main issue consists in conjugating the growing demand for personal mobility with the safeguard of the environment, providing for policies aimed at discouraging the use of private cars and increasing the use of alternative low-impact energy sources.

In this context, the paper aims to analyze the effectiveness of a collective transport system which, being powered by renewable sources and designed to reduce the private car flow directed to and coming from the Mediterranea University of Reggio Calabria, is an example of sustainable urban mobility action.

To fulfill this purpose the expected outcome generated by the described measure has been evaluated by both the economic and environmental point of view.
\end{abstract}

Keywords: Smart city, Air pollution assessment, Transport policy, Photovoltaic plant, Net present cost.

\section{INTRODUCTION}

Our industrial civilization is at a crossroads. Oil and other fossil fuels that make the current lifestyle possible are running out. Oil based technologies are close to being obsolete and the related industrial infrastructures need maintenance.

In addition, climate changes caused by activities based on fossil fuels are acknowledged to be an alteration that threatens to destabilize the planet's ecosystems [1].

In this context the European Union, undertaking policies aimed at reducing both energy consumptions and pollutant emissions, has laid out the basis for a sustainable and zeroemission economic era. Specifically, since energy consumptions are mainly due to the building industry and to the transport sector, urban settlements, where these consumptions are mostly concentrated, represent the explicit target of EU policies [2]. The measures adopted to face these challenges are crucial with a view to fulfilling the smart and sustainable society designed by the European strategy as a goal to be reached by 2020 and beyond.

Particularly among the factors influencing the quality of urban life, environment and public health [3], urban traffic plays a pivotal role [4]. Presently, in fact, urban transportation systems, affected by the mobility demand growth and unbalanced for the predominance of private transport, are becoming unsustainable.

In general, in Europe private road transport represents the largest share of the modal split regarding both passengers and freight [5-6], so that, due to the growing number of vehicles traveling on roads and highways, the age of the vehicular fleet and the massive use of highly pollutant fuels, heavily compromise the environmental quality.

In this regard, indeed, the European directives on sustainable mobility commit the Member States to adopt specific laws ruling urban transports, which have to be mainly aimed at the improvement of the fuel quality, the usage of diversified energy sources, the improvement of emission Standards and the promotion of good practices.

After this, Italian legislation has adopted strategies mainly focused on the use of low impact fuels, car fleet renewal, and modification of the modal split with a view to enhancing the share of the public transport by improving its efficiency.

Hopefully, in the next years, even though the mobility based on passenger cars is supposed to maintain a pivotal role in the planning of transport policies, the promotion of alternative and more sustainable systems (public transport, electric vehicles, etc.) should represent the main target of the strategies addressing the issue of sustainable mobility in urban area. This is the current main challenge for politicians, planners and administrators, actually compelled to strike a balance between the growing mobility demand and the necessity of reducing the impacts on the environment. 


\section{CASE STUDY. CABLE RAILWAY IN THE CITY OF REGGIO CALABRIA}

As a case study, a measure of sustainable mobility, to be implemented in the city of Reggio Calabria, is proposed. It consists of a transport system in its own protected lane, powered by a photovoltaic system, at the service of the University campus.

\subsection{Characteristics of the transportation system}

In Reggio Calabria the University buildings are situated in a campus, located in the Northern area of the city, about $2 \mathrm{~km}$ distance from its center. Presently, in the absence of an integrated public transport system serving University users, the features of public transport are not very attractive, being the connection to the nodes of modal interchange and to the city center lacking and inefficient, thus making private cars the most used transportation mode.

In order to satisfy students' increasing mobility demand and reduce the incidence of private transport toward the University campus, an advanced public transport system has been designed.

It consists in a transmission line cable in its own protected lane [7], connecting the campus with two strategic interchange poles of the city, the harbor and the Reggio Lido railway station. The system is constituted by a multiple shuttle, with only one runway for the two travel directions and with interchange areas for the crossing of vehicles located in correspondence of the intermediate stations. The vehicles placed on special rails, are driven by a steel cable, driven by a proper motor.

The track consists of two terminal stations, an upstream (Engineering Departments), working as driving station, and a valley (Lido Station), in which the vehicle can reverse its travel direction; four intermediate stations are used for passenger embarkation and for vehicle crossing (Figure 1). In addition, a station has the function of connecting the two cable rings of the line, in order to reduce the excessive length of a single rope. The track length is $1860 \mathrm{~m}$, its slope is variable between 3 and $10 \%$ and the average distance between stations is about $370 \mathrm{~m}$. The infrastructure is made of steel profiles, on which the tires roll. To prevent transverse movements of the vehicle, the system is also equipped of rubber wheels, with vertical axis.

In order to reduce $\mathrm{CO}_{2}$ emissions due to the electricity production for the system energy supply, a grid-connected PV plant, integrated into the funicular railway system, generates part of the required electricity. In this way more environmental benefits can be obtained, beyond those afforded by traffic reduction.

\subsection{Design of the photovoltaic system}

Several design choices have been assumed in order to make the PV system able to supply power to the cable railway transportation system. Particularly, three different types of panels (in monocrystalline, polycrystalline, and amorphous silicon) have been selected, placing them on different surfaces: only on the roof of the stations or, in addition, on the whole railway track canopy. Preliminarily, however, the power of the system and the energy required for its operation have been determined.

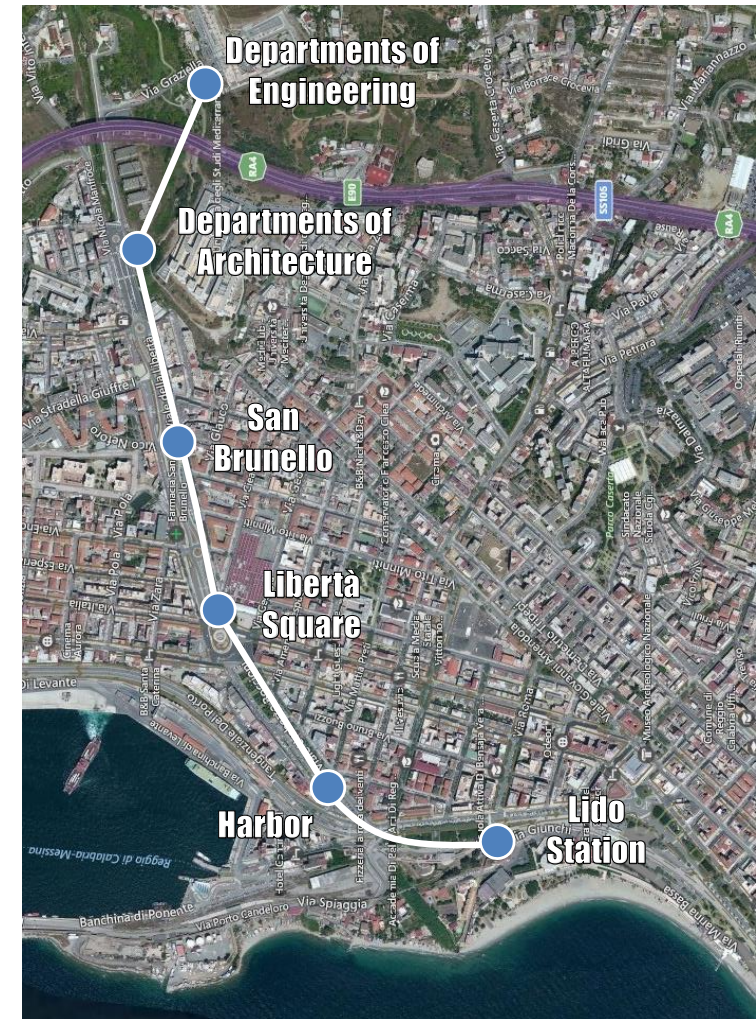

Figure 1. Route of the proposed system

\subsubsection{System power and energy demand}

The time-speed diagram adopted for the train running between two successive stations is trapezium type, consisting of three phases: acceleration, regime and deceleration (Figure 2).

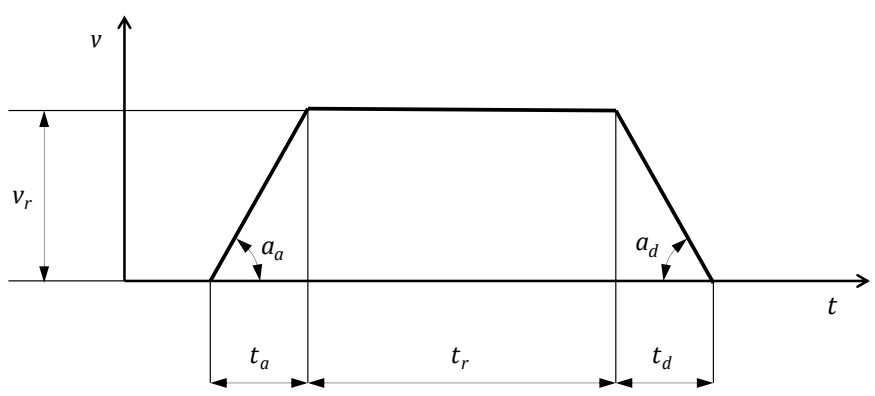

Figure 2. Time-speed diagram adopted for the system

In this hypothesis, the duration of the acceleration and deceleration phases, respectively $t_{a}$ and $t_{d}$, are expressed by the following equations:

$$
t_{a}=\frac{v_{r}}{a_{a}} ; \quad t_{d}=\frac{v_{r}}{a_{d}}
$$

in which $v_{r}$ is the regime speed of the train, $a_{a}$ and $a_{d}$ the acceleration and the deceleration in the respective phases.

As a consequence, distances respectively covered during the two phases, $d_{a}$ and $d_{d}$, are given by:

$d_{a}=\frac{a_{a} t_{a}^{2}}{2}=\frac{v_{r}{ }^{2}}{2 a_{a}} ; \quad d_{d}=\frac{a_{d} t_{d}^{2}}{2}=\frac{v_{r}{ }^{2}}{2 a_{d}}$

Instead, during the regime phase, the travel time is: 
$t_{r}=\frac{d_{r}}{v_{r}}$

and the covered distance, $d_{r}$, is:

$d_{r}=L_{T}-d_{a}-d_{d}$

where $L_{T}$ is the length of the section. Finally:

$t_{r}=\frac{d_{r}}{v_{r}}=\frac{L_{T}-d_{a}-d_{d}}{v_{r}}$

Energy demand for each lap has been calculated as a function of the system power in the different driving phases (in both peak and soft hours) and of their respective travel times:

$\left.E\right|_{l} ^{k}=2 \times \sum_{i=1}^{N_{t}}\left(\left.P_{a}\right|^{k} t_{a, i}+\left.P_{r}\right|^{k} t_{r, i}+\left.P_{d}\right|^{k} t_{d, i}\right)$

where:

- the $k$ apex indicates the peak or soft period;

- the $l$ index indicates the generic lap;

- the $i$ index indicates the generic section between two subsequent stations;

- $\quad N_{t}$ is the number of section;

- $\quad P_{a}, P_{r}$ and $P_{d}$ are the power in the acceleration, regime and deceleration phases;

- $\quad t_{a}, t_{r}$ and $t_{d}$ are the travel times during the acceleration, regime and deceleration phases.

Daily consumption, different in weekday or holiday, is a function of the number of daily trips in the respective $k$ (peak or soft) period:

$$
\left.E\right|_{d, m}=\left.\sum_{k=1}^{2} E\right|_{d, m} ^{k}=\sum_{k=1}^{2}\left(\left.h\right|_{m} ^{k} \times\left. n_{c}\right|_{m} ^{k} \times\left. f\right|_{m} ^{k} \times\left. E\right|_{l} ^{k}\right)
$$

in which:

- the $d$ index indicates the day;

- $\quad$ the $m$ index indicates the peak or soft period;

- $h$ are the daily working hours;

- $\quad n_{c}$ is the number of simultaneously on line trains;

- $\quad f$ is the frequency of service.

Finally, yearly required energy, $\left.E\right|_{y}$, is calculated as a function of the total operation days of the system, $N_{g, m}$ :

$\left.E\right|_{y}=\sum_{m=1}^{2}\left(N_{g, m} \times\left. E\right|_{d, m}\right)$

Regime speed of $8 \mathrm{~m} / \mathrm{s}(29 \mathrm{~km} / \mathrm{h})$, acceleration and deceleration of $0.8 \mathrm{~m} / \mathrm{s}^{2}$ have respectively been assumed.

Subsequently, the number of trains simultaneously driving on the track has been estimated from the required hourly flow [7]. Particularly three trains with three carriages each (40 seats/carriage) are necessary in the peak period, whereas only two trains endowed with two carriages are required in the soft one. Finally, the maximum power in the acceleration phase has been determined in relation to the number of carriages respectively running in the peak and soft hours. Table 1 reports the main characteristics of the analyzed system.
365 operating days, 240 of which are weekdays and 125 holidays, have been assumed. On the basis of the described assumptions, the required yearly energy is $476 \mathrm{MWh} /$ year.

\subsubsection{Analysis of energy production}

The available area for the installation of photovoltaic panels has preliminary been identified. The station roof surface resulted equal to $3200 \mathrm{~m}^{2}$, whereas the total area of the station roof and the railway track canopy was equal to $11000 \mathrm{~m}^{2}$.

Table 1. Characteristics of the transport system

\begin{tabular}{|c|c|c|c|}
\hline Parameter & Symbol & $\begin{array}{l}\text { Peak } \\
\text { hours }\end{array}$ & $\begin{array}{l}\text { Soft } \\
\text { hours }\end{array}$ \\
\hline $\begin{array}{l}\text { Maximum power } \\
\text { (acceleration phase) }\end{array}$ & $P_{a}\left(\mathrm{~kW}\right.$ train $\left.^{-1}\right)$ & 100 & 70 \\
\hline $\begin{array}{l}\text { Maximum power (regime } \\
\text { phase) }\end{array}$ & $P_{r}\left(\mathrm{~kW} \operatorname{train}^{-1}\right)$ & 60 & 42 \\
\hline $\begin{array}{l}\text { Maximum power } \\
\text { (deceleration phase) }\end{array}$ & $P_{d}\left(\mathrm{~kW} \operatorname{train}^{-1}\right)$ & 60 & 42 \\
\hline Frequency & $f\left(\right.$ trip $\left.\operatorname{train}^{-1} \mathrm{~h}^{-1}\right)$ & 4 & 2 \\
\hline $\begin{array}{l}\text { Train simultaneously on } \\
\text { the track }\end{array}$ & $n_{c}($ train $)$ & 4 & 3 \\
\hline Number of train carriage & (carriage train $^{-1}$ ) & 3 & 2 \\
\hline $\begin{array}{l}\text { Daily operating hours } \\
\text { (weekdays) }\end{array}$ & $h(\mathrm{~h})$ & 8 & 8 \\
\hline $\begin{array}{l}\text { Daily operating hours } \\
\text { (holydays) }\end{array}$ & $h(\mathrm{~h})$ & 0 & 16 \\
\hline
\end{tabular}

In relation to both surfaces and to the three selected panel typologies, whose technical characteristics are reported in Table 2, the total power of the PV plant has been determined (Table 3). Subsequently, using Homer software [8], the yearly produced energy has been calculated, pointing out the purchased and sold rates (Tables 4-5 and Figure 3).

The simulations showed that the energy produced, on an annual basis, is always greater than the energy demand, except when amorphous silicon panels are placed on the station roof only; in this case an integration with an energy withdrawal from the grid is needed.

Obviously, in all the cases, an energy withdrawal from the grid is required in the periods of insufficient or lacking energy production. The exceeding energy production is always sent to the grid.

Table 2. Technical characteristics of the PV panels

\begin{tabular}{lllll}
\hline Panel typology & $\begin{array}{l}\text { Peak power } \\
(\mathrm{Wp})\end{array}$ & $\begin{array}{l}\eta \\
(\%)\end{array}$ & $\begin{array}{l}\text { NOCT } \\
\left({ }^{\circ} \mathrm{C}\right)\end{array}$ & $\begin{array}{l}\beta \\
\left(\% /{ }^{\circ} \mathrm{C}\right)\end{array}$ \\
\hline Amorphous & 135 & 9,6 & 46 & $-0,24$ \\
Polycrystalline & 230 & 14,1 & 47 & $-0,45$ \\
Monocrystalline & 327 & 20,1 & 45 & $-0,38$ \\
\hline
\end{tabular}

Table 3. Peak power of the various configurations of the PV plant

\begin{tabular}{|c|c|c|}
\hline \multirow[b]{2}{*}{ Panel typology } & \multicolumn{2}{|c|}{$\begin{array}{l}\text { Peak power of the plant } \\
\left(\mathrm{kW}_{\mathrm{p}}\right)\end{array}$} \\
\hline & $\begin{array}{l}\text { Installed on the } \\
\text { station roof }\end{array}$ & $\begin{array}{l}\text { Installed on the railway } \\
\text { track canopy and on } \\
\text { the station roof }\end{array}$ \\
\hline Amorphous & 308 & 1020 \\
\hline Polycrystalline & 446 & 1468 \\
\hline Monocrystalline & 642 & 2193 \\
\hline
\end{tabular}


Table 4. Energy rates when PV panels cover the canopy of the stations only

\begin{tabular}{llll}
\hline \multirow{2}{*}{ Panel typology } & \multicolumn{2}{l}{ Energy rates $(\mathrm{MWh} / \mathrm{year})$} \\
\cline { 2 - 4 } & Produced & To the grid & From the grid \\
\hline Amorphous & 438 & 183 & 284 \\
Polycrystalline & 622 & 317 & 242 \\
Monocrystalline & 910 & 551 & 209 \\
\hline
\end{tabular}

Table 5. Energy rates when PV panels cover the canopy of the stations and of the whole railway track

\begin{tabular}{llll}
\hline \multirow{2}{*}{ Panel typology } & \multicolumn{2}{l}{ Energy rates (MWh/year) } \\
\cline { 2 - 4 } & Produced & To the grid & From the grid \\
\hline Amorphous & 1451 & 1017 & 181 \\
Polycrystalline & 2052 & 1544 & 164 \\
Monocrystalline & 3109 & 2486 & 151 \\
\hline
\end{tabular}

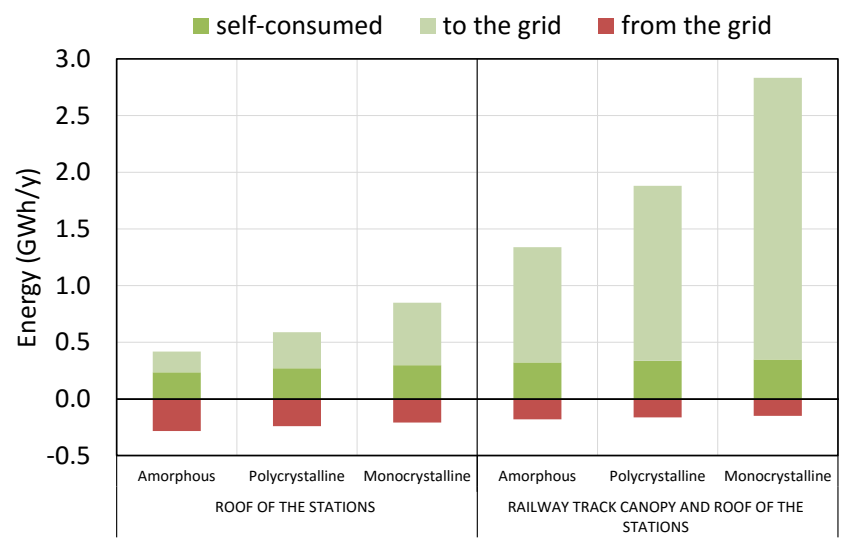

Figure 3. Yearly self-consumed, sold and purchased energy

\section{ECONOMIC ANALYSIS}

The economic analysis of the designed system has been carried out assessing the Net Present Cost (NPC):

$$
N P C=\sum_{j=1}^{n} \frac{C_{j}-B_{j}}{(1+r)^{j}}+I_{0}
$$

where $C_{j}$ and $B_{j}$ are respectively the costs and the revenues that occur within the $\mathrm{j}^{\text {th }}$ year, $I_{0}$ is the cost of the whole investment, $r$ is the discount rate, $n$ is the number of years forming the project lifetime.

The cost of the investment incorporates the cost of the PV plant and its supporting structures, whereas, for the analyzed cases, yearly costs and revenues are due to energy purchases and sells respectively.

In order to estimate their value, average tariffs were singled out. Assuming that the energy sell to the grid is ruled by the dedicated withdrawal regime [9], the electricity withdrawal price, which is equal to the hourly zonal price on the power exchange, is $0.048 € / \mathrm{kWh}$, with a yearly operating cost of $0.6 € / \mathrm{kW}_{\mathrm{p}}$.

In addition, with a view to calculating the annual revenue $B_{j}$, the possible profits derived from white certificate schemes, also known as Energy Efficiency Titles (EET), have been considered. In this case the incomes, which, for the Italian law, only regard the first five years, are yielded by EET trades and a price of $110 € /$ toe has been esteemed [10].

As a consequence, the annual revenues are:
$B_{j}=0.048 \times E_{w, j}+110 \times E_{w P, j}$ if $j \leq 5$

$$
B_{j}=0.048 \times E_{w, j} \text { if } j>5
$$

where $E_{w, j}$ is the withdrawn electricity during the year $j, E_{w P, j}$ is the primary energy delivered to the grid during the year $j$.

As far as the energy purchase is concerned, in order to esteem the annual cost, the Single National Price (SNP) settled by the Italian Authority [9] has been used. Its value is equal to $0.10 € / \mathrm{kWh}$.

Consequently, the annual costs are:

$$
C_{j}=0.10 \times E_{p, j}+0.6 \times P_{p}
$$

where $E_{p, j}$ is the purchased energy during year $j, P_{p}$ is the peak power of the PV plant.

Finally, assuming a discount rate $r=3 \%$, the results reported in Tables 6-7 were obtained, where the global amount of the initial investment $I_{0}$, the yearly cash flow $F_{j}=$ $C_{j}-B_{j}$ and the NPC at the end of the project lifetime $(n=25)$ are shown.

Specifically, Table 6 reports the outcomes related to the case in which only the canopy of the stop stations is covered with PV panels, whereas Table 7 is referred to the case in which also the whole cable railway path is covered. For both cases the reported outcomes refer to all the analyzed configurations of the project, which differ for the presence of the PV plant and for the PV module typology.

In order to single out the most cost-effective solution, the cases reported in Tables 6 and 7, in which the transportation system is equipped with a PV plant, have been compared to the configuration without PV generation, in which the needed electricity is delivered by the grid. In this last case the cash flow is $47558 € / y$ and the NPC is $828129 €$.

Table 6. Costs and revenues PV panels cover the canopy of the stations only

\begin{tabular}{llll}
\hline Panel typology & $\begin{array}{l}\text { Initial } \\
\text { investment } I_{0} \\
(€)\end{array}$ & $\begin{array}{l}\text { Cash Flow } \\
F_{j} \\
(€ / \text { anno })\end{array}$ & $\begin{array}{l}\text { NPC } \\
(€)\end{array}$ \\
\hline $\begin{array}{l}\text { Amorphous silicon } \\
\text { PV panels }\end{array}$ & 184680 & 19777 & 511934 \\
$\begin{array}{l}\text { Polycrystalline } \\
\text { silicon PV panels }\end{array}$ & 374228 & 9186 & 504470 \\
$\begin{array}{l}\text { Monocrystalline } \\
\text { silicon PV panels }\end{array}$ & 769889 & -5114 & 628944 \\
\hline
\end{tabular}

\begin{tabular}{|c|c|c|c|}
\hline Panel typology & $\begin{array}{l}\text { Initial } \\
\text { investment } I_{0} \\
(€)\end{array}$ & $\begin{array}{l}\text { Cash Flow } \\
F_{j} \\
(€ / \text { anno) } \\
\end{array}$ & $\begin{array}{l}\text { NPC } \\
(€)\end{array}$ \\
\hline $\begin{array}{l}\text { Amorphous silicon } \\
\text { PV panels }\end{array}$ & 2092906 & -30079 & 1473417 \\
\hline $\begin{array}{l}\text { Polycrystalline } \\
\text { silicon PV panels }\end{array}$ & 2700822 & -56867 & 1565497 \\
\hline $\begin{array}{l}\text { Monocrystalline } \\
\text { silicon PV panels }\end{array}$ & 4178656 & -102932 & 2152532 \\
\hline
\end{tabular}

Table 7. Costs and revenues PV plant covers the canopy of the whole railway path

The results of this comparison are reported in Figure 4, where the $N P C$ values at the end of the project lifetime ( $n=$ 25 years), for all the considered configurations, are plotted. 
It is worth noting that, from an economic point of view, the optimal configuration is the one that entails the installation of the PV panels on the canopy of the stations only. As a matter of fact, in this condition, the minimum NPC values have been assessed.

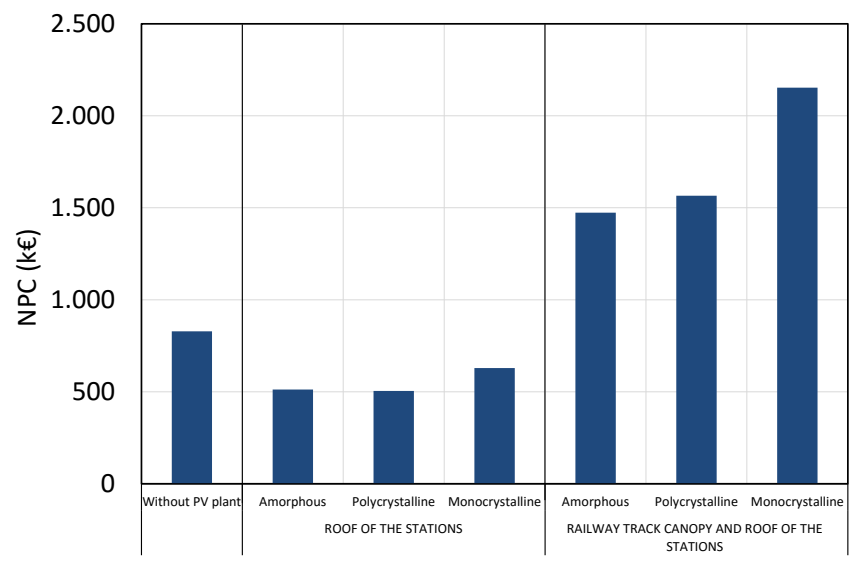

Figure 4. NPC for the analyzed configurations

\section{POLLUTANT EMISSION ASSESSMENT}

Two pollutant typologies were analyzed: the first one regards the emissions having a local impact [11] on the environment and consists of the combustion products discharged by vehicles in the University area (CO, NMVOC, $\mathrm{NOx}, \mathrm{NH}_{3}, \mathrm{PM}, \mathrm{N}_{2} \mathrm{O}$ ); the second one involves the emissions having a large scale action and was assessed in terms of $\mathrm{CO}_{2}$ rate [12]. Both vehicle fleet and cable railway, which is electrically powered, are source of this last type of pollutant.

\subsection{Assessment of the pollutant emissions having a local impact on the environment}

Being the cable railway electrically powered, the studied fleet is the only source of pollutant with local impact. It is constituted by the road vehicles (passenger cars or motorcycles) involved in the movements directed towards or coming from the Mediterranea University of Reggio Calabria.

Obviously, these vehicle flows are modified by the construction of the new transportation system, as well as the related emissions. Therefore, while the current flows were assessed by means of sample measurements regarding the actual fleet, predictions based on reliable hypothesis were made to evaluate the possible flow evolution after the implementation of the new system.

The daily amount of emissions discharged by the specified road vehicles were assessed in correspondence of the two configurations. In this aim the TIER 1 method of the dell'EMEP/EEA emission inventory guidebook 2009 [13] was used.

Accordingly to this procedure, the fleet has to be split up into classes which comprise vehicles homogeneous for the rates of the emissions discharged in the environment. In this view, the daily emission amount of the pollutant $i$ discharged by all the vehicles composing the fleet, $E_{i}$, is assessable as:

$$
E_{i}=\sum_{v=1}^{N_{v}} n_{v} \times C_{v} \times F E_{i, v}
$$

where:

- $N_{v}$ is the number of vehicle classes;

- $n_{v}$ is the number of vehicles belonging to class $v$;

- $C_{\mathrm{v}}$ is the daily fuel consumption of the average vehicle belonging to class $v$;

- $F E_{\mathrm{i}, \mathrm{v}}$ is the emission factor of the vehicle belonging to class $v$ and related to the pollutant $i$.

The emission factors [13] related to every considered pollutant having a local impact on the environment are reported in Table 8 .

Table 8. Emission factors for pollutants emitted by vehicles [13]

\begin{tabular}{llll}
\hline \multirow{2}{*}{ Pollutant } & \multicolumn{2}{l}{$\begin{array}{l}\text { Emission factor }(\mathrm{g} / \mathrm{kg} \text { fuel }) \\
\text { Cars }\end{array}$} & Motorcycles \\
\cline { 2 - 4 } & Gasoline & Diesel & Gasoline \\
\hline $\mathrm{CO}$ & 132 & 4.7 & 490 \\
$\mathrm{NMVOC}$ & 14 & 1.1 & 114 \\
$\mathrm{NO}_{\mathbf{x}}$ & 14.5 & 11 & 9.5 \\
$\mathrm{PM}$ & 0.037 & 1.7 & 2.7 \\
$\mathrm{~N}_{2} \mathrm{O}$ & 0.213 & 0.087 & 0.059 \\
$\mathrm{NH}_{3}$ & 0.173 & 0.018 & 0.063 \\
\hline
\end{tabular}

The daily fuel consumption of the average vehicle belonging to category $v$ was evaluated by means of the following expression:

$C_{v}=c_{v} \times d$

where $c_{v}$ is the specific consumption of the vehicle $v$ and $d$ is the average length of the typical trip (Table 9), assumed equal to $3 \mathrm{~km}$.

Table 9. Consumptions of the analyzed vehicles [13]

\begin{tabular}{llll}
\hline \multirow{2}{*}{ Consumption } & Cars & & Motorcycles \\
\cline { 2 - 4 } & Gasoline & Diesel & Gasoline \\
\hline specific $(\mathrm{g} / \mathrm{km})$ & 60 & 70 & 35 \\
daily $(\mathrm{kg} /$ day $)$ & 0.180 & 0.210 & 0.105 \\
\hline
\end{tabular}

As regards the structure of the current fleet, the input data needed for its assessment were derived from sample measurements regarding the actual flows. These surveys yielded that, per day, 7759 people travel by means of passenger cars whereas 1565 people use motorcycles [7].

In order to single out the vehicle classes [14] for the studied case, the composition of the fleet running in the urban area pertaining to the Municipality of Reggio Calabria was taken into account [7]. Specifically, the studied fleet can be effectively classified by fuel type, so that two categories can be distinguished: gasoline or diesel fueled vehicles. As far as passenger car is concerned, gasoline fueled vehicles are the largest share (about 62\%) of the fleet distribution by fuel, while only the remnant $38 \%$ is related to diesel cars. [7]. On the other hand, motorcycles are gasoline fueled only.

Therefore the number of vehicles of type $v$ is assessable as:

$n_{v}=\frac{Q_{v}}{t_{o, v}} p_{v}$

where: 
- $\quad n_{v}$, is the number of vehicles of type $v$ travelling every day in the considered fleet;

- $Q_{v}$ is the number of people per day travelling on the vehicle $v$;

- $\quad t_{o, v}$ is the occupancy rate of the vehicle $v$;

- $\quad p_{v}$ is the percentage of vehicles of type $v$.

Assuming an occupancy rate of 1.56 for passenger cars (whatever fueled) and of 1.30 for motorcycles, the results reported in Table 10 were derived.

Table 10. Current composition of the studied running fleet

\begin{tabular}{llll}
\hline \multirow{2}{*}{ Vehicle type } & Fuel type & \multicolumn{2}{c}{ Total } \\
\cline { 2 - 3 } & Gasoline & Diesel & \\
\hline Passenger Car & 3084 & 1890 & 4974 \\
Motorcycle & 1204 & - & 1204 \\
\hline
\end{tabular}

In order to assess the evolution of the mobility demand caused by the impact of the new transportation system, the following hypotheses were made:

1. the modal split is changed by the impact of the new system and the shift towards the collective mode has been assumed to regard an average percentage of about $25 \%$ of the former demand;

2. the new mode of transport attracts new customers and causes an enhancement of the global mobility demand, assumed equal to $5 \%$.

The results of this calculation are reported in Table 11, where the evolution of the mobility demand, divided per transport mode, is shown. Starting from the new transportation demand and assuming that the occupant rate does not change, the number of vehicles belongings to each category $v$ can be assessed by means of equation (15) and the outcome of this calculation is reported in Table 12.

Table 11. Mobility demand (people/day) after the realization of the new transportation system

\begin{tabular}{lll}
\hline Mode of transport & & \\
\hline Passenger cars & Motorcycles & Cable Railway \\
\hline 5919 & 1115 & 2752 \\
\hline
\end{tabular}

Table 12. Number of vehicles (vehicles/day) running after the realization of the new transportation system

\begin{tabular}{llll}
\hline \multirow{2}{*}{ Vehicle type } & Fuel type & & \multirow{2}{*}{ Total } \\
\cline { 2 - 3 } & Gasoline & Diesel & \\
\hline Autovetture & 2332 & 1462 & 3794 \\
Motocicli & 858 & - & 858 \\
\hline
\end{tabular}

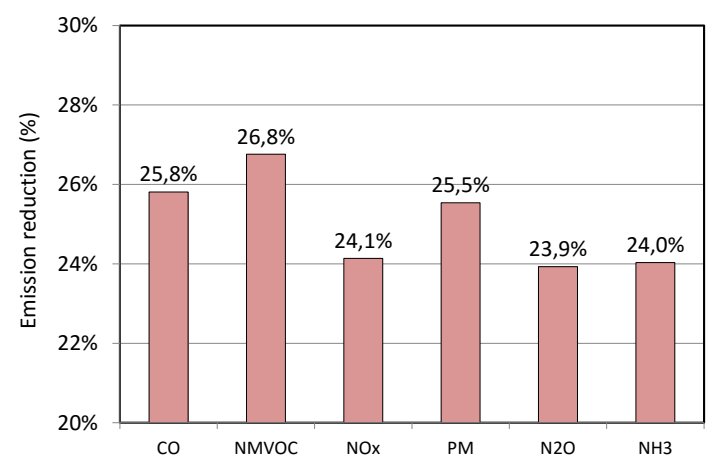

Figure 5. Emission rates before and after the implementation of the transport system
Moreover, knowing the fleet distribution, the emission rates can be calculated by means of equation (13). The results are reported in Figure 5, which shows the rate of the emissions having a local impact only. It is worth noting that the emission rate reduction is of about $25 \%$ for every pollutant. The results related to the pollutants having global impacts, expressed in terms of $\mathrm{CO}_{2}$, are reported in the following specific paragraph

\subsection{Assessment of the emission rates related to pollutants having a large scale action.}

The cable railway is electrically powered; therefore the emission rates are related to the electricity consumptions and are referred to pollutants having a global impact on the environment. Specifically, using carbon dioxide as a representative indicator of these pollutants, the annual emission rates $E_{m}$ can be assessed provided that the energy consumption $E$ and the electricity emission factor $F E_{e l}$ (equal to $0.468 \mathrm{~kg} / \mathrm{kWh}[15]$ ) are known:

$E_{m}=E \times F E_{e l}$

The emission rates were assessed for the various studied configurations which differ for the presence of the PV plant and for the typology of the PV panels. The energy consumption $E$ has been esteemed in a former paragraph using the nominal features of the engine of the transport system, its operation periods, and the characteristics of the transport service [7].

Obviously, when no PV plant is present, the needed energy is totally fed by the grid, therefore, in this case, the whole energy consumption of the transport system contributes to the emission of pollutants. On the other hand, when the PV plant partially supplies the electricity needed to power the cable railway, the energy delivered by the grid is correspondently reduced and so are the related emission rates. Specifically, their reductions is equal to the electricity emission factor times the energy supplied by the PV plant. With regard to the $\mathrm{CO}_{2}$ emissions due to the road vehicles, they were assessed, for both the ante and post operam situations, by means of the procedure detailed in the former section. The correspondent emission factors are reported in Table 13

Table 13. Emission factors for $\mathrm{CO}_{2}$ emitted by vehicles [13]

\begin{tabular}{lll}
\hline Emission factor $(\mathrm{g} / \mathrm{kg}$ fuel $)$ & \\
\hline Cars & Motorcycles \\
\hline Gasoline & Diesel & Gasoline \\
\hline 3180 & 3140 & 3180 \\
\hline
\end{tabular}

The results of the described analysis are reported in Figures 6 and 7.

Figure 6 depicts the annual emission rates discharged into the environment in correspondence of all the studied configurations and the emission rates avoided owing to the energy surplus delivered to the grid by the various typologies of PV plant (amorphous, polycrystalline or monocrystalline silicon).

Figure 7, on the other side, reports the emission rates resulted from the balance among the discharged and the avoided quantity.

It is worthy of note that the two cases respectively corresponding to the ante and post opera without PV plant configurations, are very similar (Figures 6 and 7). This is due 
to the fact that the $\mathrm{CO}_{2}$ emissions produced by the electricity consumptions of the cable railway when no PV plant is present (equal to $232 \mathrm{t} /$ year) compensate the reduction of the $\mathrm{CO}_{2}$ emission rates ( $240 \mathrm{t} /$ year) caused by the decrease of the number of circulating vehicles occurring in the post-operam situation (Figure 6).

On the contrary, the presence of the PV plant, for all the studied configurations, reduces the $\mathrm{CO}_{2}$ emissions discharged into the environment, being the electricity demand of the cable railway partially satisfied by a RES.

Furthermore, the use of more efficient types of PV plant (polycrystalline or monocrystalline silicon), with larger panel surfaces, raises the avoided emission rates (Figure 6), so that in correspondence of the optimal case (monocrystalline silicon panel covering the largest surface) the balance among discharged and avoided emissions is negative (-350 t/year Figure 7), pointing out a global benefit (advantage) for the environment.

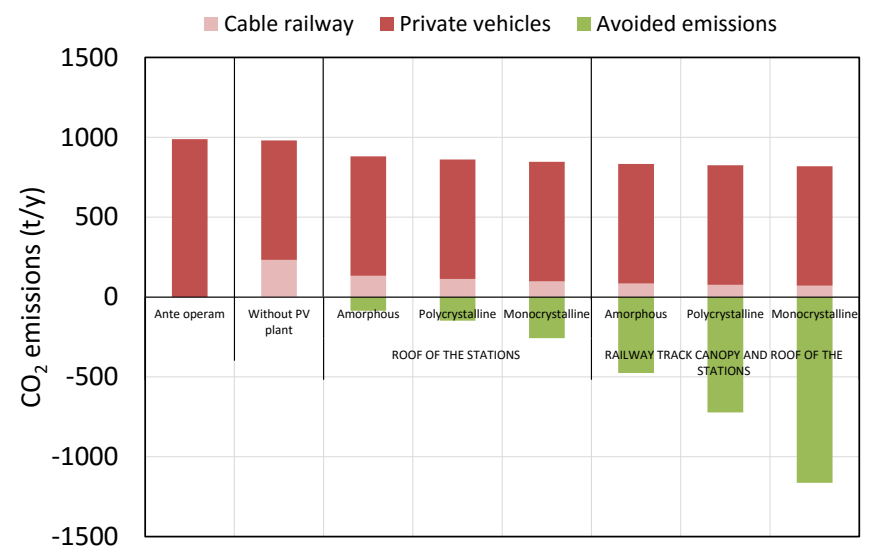

Figure 6. $\mathrm{CO}_{2}$ emissions produced and avoided by the road vehicles and by the cable railway

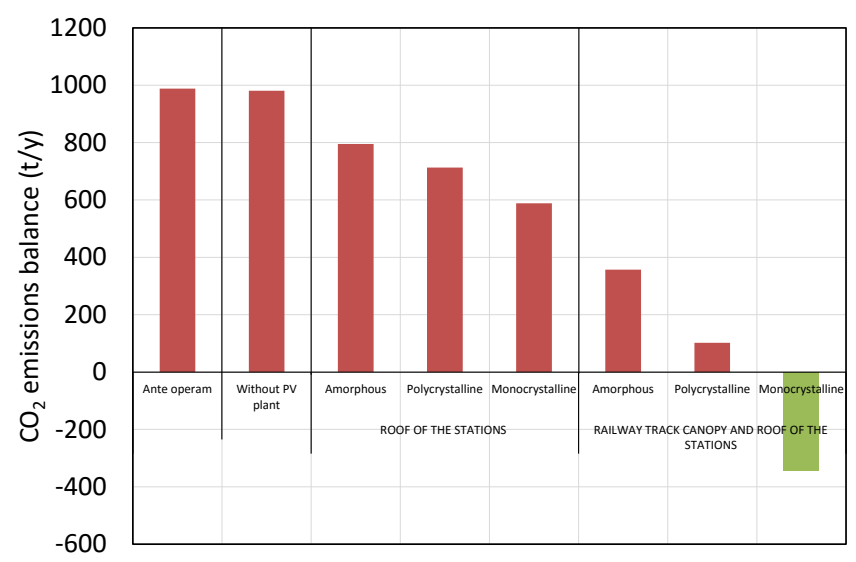

Figure 7. $\mathrm{CO}_{2}$ emission balance for the different studied configurations

Finally, in order to try to strike a balance among the economic and environmental facets of the issue, a summary of all the obtained results is reported in Figure 8.

From this representation, it can be inferred that the optimal configurations are the ones in which the transportation system is equipped with a PV plant covering the station canopies only (with a limited surface). As a matter of fact, comparing this latter case with the configuration without PV plant, a reduction of both emission rates and NPC values is registered.

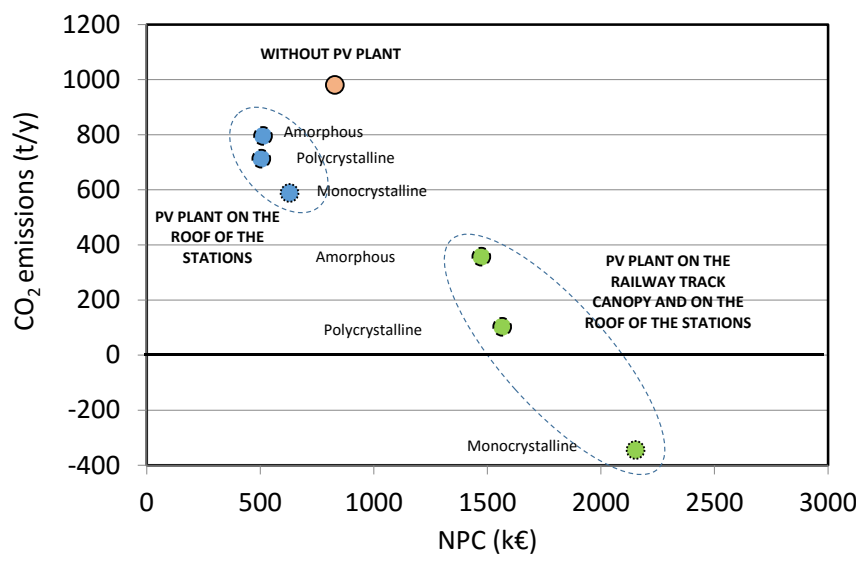

Figure 8. $\mathrm{CO}_{2}$ emission rates versus NPC values for all the studied configurations

On the other hand, albeit enhancing the PV panel surface causes a remarkable reduction of the emission rate and, hence, has a positive effect from an environmental point of view, it also provokes a noteworthy rise of the costs which should be carefully considered in the decision process regarding the project.

\section{CONCLUSIONS}

The present configuration of the mobility model is no longer sustainable. In the last years, in fact, in the cities the number of circulating vehicles has markedly increased following a trend that, although slowing down, is urgent to be inverted. New mobility models, favouring the use of shared, collective and electric transportation means, fuelled with RES, are urgent to be adopted.

Within this frame, as an example of urban sustainable mobility, the present work illustrates a cable railway to be implemented in the city of Reggio Calabria. It connects, in a dedicated track, the university campus with two important urban hubs, the harbour and a strategic railway station.

The measure produces, as far as local pollution is concerned, a $25 \%$ average reduction of pollutant emissions thanks to the smaller number of circulating vehicles. As regards $\mathrm{CO}_{2}$ emissions, on the contrary, the amount originating from the system electric power supply is comparable to the reduction obtainable for the fewer circulating vehicles, so that, on a global scale, emitted $\mathrm{CO}_{2}$ shows no substantial variation.

In the aim to reduce emissions some design options, consisting in the installation of different typologies of PV modules (monocrystalline, polycrystalline and amorphous silicon), horizontally laid on different covering surfaces of the track (station roof or, in addition, railway track canopy) have been selected. The energetic analysis has been carried out by means of Homer software, whereas the economic one has been effected evaluating the Net Present Cost.

The analysis showed that yearly produced energy is, in all cases, greater than energy demand, apart from the case in which amorphous silicon panels are laid on the smallest surface, as in such case energy from the grid is required.

From an economic point of view, the optimal configurations are the ones that entail the installation of the PV panels on the canopy of the stations only. As a matter of fact, in this condition, the minimum NPC values have been assessed. 
As concerns total $\mathrm{CO}_{2}$ emitted by both vehicles and the transport system supply, being the energy needs of this latter partially satisfied by RES, reductions are observed for all PV configurations with respect to the case of their absence.

However, only configurations in which PV plants are installed on the station covering are simultaneously cheaper and less polluting than the configuration in which power is exclusively delivered from the national electric grid.

\section{REFERENCES}

[1] IPCC, Climate change, $5^{\text {th }}$ Assessment Report, Intergovernmental Panel on Climate Change, Geneva, 2013.

[2] J. Rifkin, The Third Industrial Revolution: How Lateral Power Is Transforming Energy, the Economy, and the World, Palgrave Macmillan, 2013.

[3] ISPRA. (2014). Qualità dell'ambiente urbano, Report 53/2014, Istituto Superiore per la Protezione e la Ricerca Ambientale, Roma, Italy. [Online]. Available: http://www.isprambiente.gov.it/it/pubblicazioni/statode llambiente/

[4] EEA, Transport and Environment Reporting Mechanism, European Environment Agency, Luxembourg, 2011.

[5] European Commission. (2006). Road Transport Policy: Open Roads Across Europe, Office for Official Publications of the European Communities, 2006. [Online]. Available: http://ec.europa.eu/transport/road /doc/road_transport_policy_en.pdf

[6] ENEA, Mobility Management. Stato dell'arte $e$ prospettive, Italian National Agency for New Technologies, Energy and Sustainable Economic Development, Roma, 2001. (in Italian)

[7] D. Gattuso, Sistemi di trasporto collettivo avanzati a media potenzialità. Analisi funzionali ed economicofinanziarie, Ed. Laruffa, Reggio Calabria, Italy, 2006. (in Italian)

[8] HOMER Energy LCC. (2005). The Micropower Optimization Model. National Renewable Energy Laboratory, CO, USA. [Online]. Available: http://www. homerenergy.com

[9] GSE. (2016, Jan.). Gestore dei Servizi Energetici GSE S.p.A, [Online]. Available: http://www.gse.it/en

[10] GME. (2016, Jan.). Gestore dei Mercati Energetici S.p.A. [Online]. Available: http://www.mercatoele ttrico.org/en

[11] M. Kousoulidou, L. Ntziachristos, G. Mellios, Z. Samaras, "Road-transport emission projections to 2020 in european urban environments," Atmospheric Environment, vol. 42, no. 32, pp. 7465-7475, 2008. DOI: $10.1016 /$ j.atmosenv.2008.06.002.

[12] D. Barbieri, A. Nucara, M. Pietrafesa, G. Rizzo, "Energy and environmental issues as choosing elements for selecting options in the transportation sector aimed at reducing $\mathrm{CO}_{2}$ emissions: an application to the Italian case," in Studies in Environmental Science, vol. 65 (PART B), 1995, pp. 1193-1196.

[13] EMEP/EEA. (2013). Air Pollutant Emission Inventory Guidebook, Technical. Report N.12/2013, European Environmental Agency, Luxembourg. [Online]. Available:

http://www.eea.europa.eu/publications/emep-eeaguidebook-2013
[14] C. Marino, A. Nucara, M. Pietrafesa, "The Assessment of Road Traffic Air Pollution by Means of an Average Emission Parameter," Environmental Modeling \& Assessment, vol. 21, no. 1, pp. 53-69, 2016. DOI: 10.1007/s10666-015-9489-8.

[15] ISPRA. (2015). Fattori di emissione atmosferica di $\mathrm{CO}_{2}$ e sviluppo delle fonti rinnovabili nel settore elettrico. Report 212/2015. Istituto Superiore per la Protezione e la Ricerca Ambientale, Roma, Italy. [Online]. Available: http://www.isprambiente.gov.it/files/pubblic azioni/rapporti/R 212 15.pdf

\section{NOMENCLATURE}

\section{Symbols}

$a_{a} \quad$ acceleration, $\mathrm{m} / \mathrm{s}^{2}$

$a_{d} \quad$ deceleration, $\mathrm{m} / \mathrm{s}^{2}$

$B \quad$ benefits, $€ /$ year

$C \quad$ operating costs, $€ /$ year

$C_{v} \quad$ consumption of the vehicle of typology v, $\mathrm{g} / \mathrm{kg}_{\text {comb }}$

$d_{a} \quad$ distance covered during acceleration phase, $\mathrm{m}$

$c_{v} \quad$ specific consumption of the vehicle, $\mathrm{g} / \mathrm{km}$

$d \quad$ average distance covered, $\mathrm{km}$

$d_{d} \quad$ distance covered during deceleration phase, $\mathrm{m}$

$d_{r} \quad$ distance covered during regime phase, $\mathrm{m}$

E consumption, $\mathrm{kWh}$

$E_{i} \quad$ emission of the pollutant i, g

$f \quad$ frequency, train/h

$F E_{e l} \quad$ emission factor of the electrical energy, $\mathrm{g} / \mathrm{kWh}$

$F E_{i, v} \quad$ emission factor of the pollutant $i$, due to the vehicle of typology $v, \mathrm{~g} / \mathrm{kg}$

$h \quad$ daily operating hours, hours

$I_{0} \quad$ Investment cost, $€$

$L_{T} \quad$ length of the section, $m$

$n_{c} \quad$ number of trains simultaneously on the track, -

$n_{v} \quad$ number of vehicles, -

$N_{g} \quad$ days of operating, days

NPC Net Present Cost, $€$

$N_{t} \quad$ number of section of the track, -

$N_{v} \quad$ number of vehicle typologies, -

$P_{a} \quad$ power in acceleration phase, $\mathrm{kW}$

$P_{d} \quad$ power in deceleration phase, $\mathrm{kW}$

$P_{r} \quad$ power in regime phase, $\mathrm{kW}$

$r \quad$ discount rate, $\%$

$t_{a} \quad$ travel time in acceleration phase, $\mathrm{s}$

$t_{d} \quad$ travel time in deceleration phase, $\mathrm{s}$

$t_{r} \quad$ travel time in regime phase, $\mathrm{s}$

$v_{r} \quad$ speed of the train in the regime phase, $\mathrm{m} / \mathrm{s}$

\section{Superscripts and subscripts}

$k \quad$ peak period or soft period

$m \quad$ weekday or holyday

$i \quad$ pollutant

$v \quad$ vehicle 